\title{
APPLICATION OF INFORMATION TECHNOLOGIES IN THE EDUCATIONAL PROCESS
}

\author{
Kismetova G.N. \\ Candidate of Pedagogic Sciences, Associate Professor M.Utemisov WKU \\ Uralsk, Republic of Kazakhstan \\ Sultangazieva A.K. \\ Master student of M. Utemisov WKU
}

Abstract. This article reveals the purpose of information technology in the educational process.

Keywords: Information and educational environment, information and methodical conditions, information and communication technologies.

One of the most important places in the education system should be the study of the latest achievements in the field of computer science, its tools and methods, as well as the prospects for their further development and practical use.

Application of Information Technologies in Education allows:

- to significantly increase the efficiency of work in all types of educational activities, to obtain a greater effect at the same costs as with traditional technologies;

- to reduce the gap between the number of people wishing to receive education and the possibilities of the education system to provide it;

- to unite efforts and organize joint creativity of many teams and individual specialists, without actually producing any costs for their physical movement, provision of working areas [1].

The modern scientific and technical level of information technologies is such that they can be used to perform many routine processes of processing educational information. Modern learning systems with the use of information technologies can take on a part of the intellectual work of the teacher, for example, the control of the assimilation and academic performance of students. The basic skills and techniques that should be passed on to students are well algorithmized within such learning systems. Modern means of communication, covering the entire globe, allow you to provide access to automated learning systems at any point, both for an individual student and for entire groups.

Interactive multimedia applications for educational and reference materials contain various exercises and tasks that allow you to solve a number of didactic problems, and not only enrich the vocabulary and expand knowledge about the subject, but also turn learning into an exciting game.

The use of multimedia tools, such as a video projector, allows you to organize viewing of feature films and cartoons in the original language, which is of great practical importance for the formation of speech skills and abilities.

The use of ICT in English lessons is a requirement of the present time. The teacher spends more time preparing for the lesson, but the result is worth it, since information and communication technologies create ideal conditions for the formation of intellectual competence and creativity of students. The use of these tools in the classroom helps to create an atmosphere of mutual understanding and cooperation between children in the classroom, stimulates activity and creativity in students, forms a positive attitude to learning activities, and develops motivation. In our lessons, we use such technical means as audio, video, computer, and projector. All these technical tools help us to successfully cope with the tasks of the modern educational system. Interactive learning based on multimedia programs allows us to implement methodological, didactic, pedagogical and psychological principles, makes the learning process entertaining and creative. Multimedia presentations are actively used in the learning process. Students use the Internet to find material and prepare a project.

Currently, significant changes in the field of education have also affected the teaching of a foreign language in school. In particular, new information technologies, such as the use of Internet resources, training computer programs, etc., have become intensively introduced into the educational process.

Such researchers as Polat E. S., Dmitrieva E. I., Novikov S. V., Polilova T. A., Tsvetkova L. A., etc. are actively engaged in the development and implementation of new information technologies in the educational process. Therefore, O.I. Rudenko-Morgun in his article "Computer technologies as a new form of education" writes that we live in the age of the information, computer revolution, which began in the mid-80s and continues to accelerate. Here are its main milestones: the emergence of the personal computer, the invention of multimedia technology, the introduction of the global information computer network Internet into our lives. All these innovations easily and imperceptibly entered life: they are widely used in almost all professional spheres and in everyday life [2].

Computer training programs in teaching English, according to E. L. Nosenko [3], began to be used since the 80s of the XX century. It was said that automated training systems (ATS) belong to the so-called combined technical teaching aids. They are designed to implement with the help of a computer, working in an interactive mode, the functions of presenting educational information in an easy-to-understand form, individualized management of educational activities in the course of programmed, problem-based learning; knowledge control, as well as to provide access to computing, information and reference ond computer resources. "The fact that computers have rapidly entered our lives and the process of teaching English, somewhat pushing traditional 
methods and forcing teachers of foreign languages to solve problems that no linguist even suspected a few decades ago" writes S. V. Fadeev [4]. It is not surprising that not all teachers were ready for the widespread introduction of computers in such an unconventional field as teaching foreign languages.

As practice shows, of all the existing teaching aids, computers are the best "fit" into the structure of the educational process, most fully meet didactic requirements and bring the process of teaching English as close as possible to real conditions. Computers can perceive new information, process it in a certain way and make decisions, can memorize the necessary data, reproduce moving images, control the operation of such technical teaching aids as speech synthesizers, video recorders, tape recorders. Computers significantly expand the possibilities of teachers to individualize teaching and enhance the cognitive activity of students in teaching English, allow them to adapt the learning process to the individual characteristics of students as much as possible. Each student gets the opportunity to work at his own pace, i.e. choosing for themselves the optimal volume and rate of assimilation of the material [3]. The use of computers in English lessons significantly increases the intensity of the educational process. With computer learning, a much larger amount of material is assimilated than it was done at the same time in the conditions of traditional learning. In addition, Rubenstein S.L., believes that the material is assimilated more firmly when using a computer.

However, after talking about the advantages of computers, Nosenko E. L., Lomov B. T. note some disadvantages. The dialectical nature of pedagogical phenomena consists in the fact that any property or quality of an integral educational process that is positive in itself turns into its opposite and becomes extremely undesirable with an immoderate, hypertrophied manifestation that suppresses other, no less important properties. This remark is most directly related to the individualization of learning, especially since in the context of computerization, the conditions for interaction between the teacher and students, as well as students with each other, change significantly.

Already at the first stage of teaching English, in the process of setting goals and objectives for the upcoming cognitive activity of students, the teacher participates indirectly. The direct presentation of tasks to the student is carried out by the computer. Of course, the teacher should take the most active part in the preparation of training programs that determine the sequence of student actions in solving a particular problem. However, in the implementation of the most important psychological and pedagogical function of teaching - the presentation and acceptance by students of the goals and objectives of educational and cognitive activity - under conditions of computerization, an acute deficit of direct communication between the teacher and the student, the living word of the teacher, is possible.

Motivation management, learning FL is one of the central problems of teaching methods in school. The FL as an object has a number of specific features, one of which is the mastery of the FL by teaching the ability to communicate in the FL. Unfortunately, now, training in FL is mainly artificial and educational in nature due to the lack of a "natural need" for schoolchildren to communicate in FL.

The most important factor stimulating the process of foreign language speech communication should be considered the motivation for mastering the foreign language. In recent years, this problem has been investigated within the framework of the activity approach to learning developed by S. L. Rubinstein, A. N. Leontiev and others [5]. In foreign literature, much attention is paid to the role of motivation, called by foreign authors "Motor", "Key-word" in teaching foreign language.

Based on the above works, we will understand by motivation a system of stimulating impulses that direct educational activity, in the case of a positive attitude of the teacher, to a deeper study of the foreign language, its improvement and the desire to develop the needs of knowledge of foreign language speech activity. Numerous experiments have shown that for one academic year, the ratio of students to different types of speech activities (SA) in the FL could change dramatically in a negative or positive way. This, in turn, depends on the teacher's style of work (the constant use of only one textbook, monotonous types of exercises weakens positive emotions, and the student turns into a passive contemplator), on the teaching materials, on learning outcomes, etc.

Thus, the experiment of N.M.Simonova showed that the higher the academic performance in FL, the deeper in the student's subconscious mind is the positive attitude towards the study of FL. Conversely, low academic performance is strongly correlated with negative cognitive, mnemonic, and communicative attitudes [6].

A positive attitude towards the study of foreign language contributes to the improvement of the results of learning SA.

There are many computer programs available to assist the English teacher and student in mastering the English language. Computer based teaching programs have many advantages over traditional teaching methods. They allow you to train various types of speech activity and combine them in different combinations, help to understand linguistic phenomena, form linguistic abilities, create communicative situations, automate language and speech actions, and also provide the ability to take into account the leading representative system, implement an individual approach and intensify the student's independent work.

Let's analyze some of them.

a). Learning vocabulary.

When introducing and practicing thematic vocabulary, such as shopping, food, clothing, etc., you can use the computer programs "Triple play plus in English", "English on holidays", "English Gold 'and others. The stages of working with computer programs are as follows: demonstration, consolidation, control. 
Using the example of the computer program "English on holidays", we will consider these stages.

At the first stage - the introduction of vocabulary, for example, on the topic "Weather". Using the demo computer, the teacher selects the automatic mode: images of natural phenomena appear on the screen: снег-snow, ливень-shower, гроза-thunderstorm, пасмурно-humidity, изморозь-drizzle, ясно-clear, солнечно-sunny, холодно-соld, облачноcloudy, град-hail etc.

Then the phrases follow:

What a beautiful day! - Какой прекрасный день!

What awful weather! - Какая ужасная погода!

Is it usually as hot as this? - Здесь всегда так жарко?

What's the forecast for tomorrow? - Какой прогноз погоды на завтра?

It's windy! - Дует сильный ветер!

It's raining - Идёт дождь.

Students watch and listen. The working time is approximately 1 minute.

At the second stage, we are working on working out the pronunciation and fixing the vocabulary. The teacher or student switches the program from automatic mode to normal mode by clicking the mouse and pointing the arrow at the desired word or phrase. Students repeat after the speaker in a chorus. If there are several computers in the classroom, students work individually or in pairs, using headphones and a microphone. The working time is about 5-10 minutes, it depends on the number of words of the topic being studied.

At the third stage, the control of the studied vocabulary is carried out. Students choose a task that contains a different number of questions on the topic: 10,20,30. At the end of the exam, a table of results in percentages appears on the screen. Of course, every student strives to achieve the best results. If there is only one computer in the class, it is used as a demonstration when introducing and front-fixing vocabulary. The control of thematic vocabulary can be carried out individually using the handout material - cards. The tasks on the cards can be similar to the tasks of a computer program, for example:

- Indicate the correct translation option - tennis, shower, snow, umbrella, thunderstorm, boxing, basketball

- Which of the written words is superfluous in meaning winter, February, cool, December, November, January и Т. п.

The computer program "English on holidays" covers lexical material on the topic "City" and allows you to control the vocabulary in all sections of the topic at once. In this case, more questions are offered: 60, 90, 120.

b). Practicing pronunciation.

Many training programs provide a mode of working with a microphone. After listening to a word or phrase, the student repeats after the speaker and a graphic image of the sound of the speaker and the student appears on the screen, when comparing which all the inaccuracies are visible. The student strives to achieve a graphic representation of the spoken sound as close as possible to the sample.

c). Teaching dialogic speech.

An example of working with the dialogs of the computer program "Triple play plus in English". From the suggested 12 dialogs, one is selected, for example, "In a cafe". Several images - scenes of this dialog appear on the screen.

I - stage - acquaintance with the dialogue.

- Good morning!

- Good morning!

- What would you like?

- I'd like some coffee, please.

- Do you want milk in your coffee?

- Yes, please.

- Hey, this coffee is too cold.

- I'm sorry. Here is some hot coffee.

- Thank you.

- How is it now?

- It's just right.

- Would you like some more coffee?

- No, thanks.

- How much is it?

- Ninety - five cents, please.

- Thank you. Have a nice day.

- Good bye.

II - stage - learning the dialogue.

If there are multiple computers in the classroom, students work in pairs or groups of 3 . They repeat phrases after the speaker, here the mode of working with a microphone can also be used. Younger schoolchildren can do exercises for 
composing these sentences from a group of words, for example: like, lyke, what, you, wood, your, yu, would. The student moves the arrow to the desired word, clicks the mouse to make a sentence What would you like? etc. The number of correct suggestions is reflected on the screen. Thus, students learn spelling and learn dialogue in a playful way.

III - stage - dramatization of the dialogue.

Students reproduce the dialogue, first based on pictures, and then stage it on their own.

The next stage is the control of dialogical speech after studying all 12 dialogues. Students choose a card with an assignment (the teacher himself prepares cards with a description of the situation) and make up their own dialogue, using the vocabulary of this program and showing their imagination.

d). Learning to write.

This type of work solves two problems at once: the correct spelling of English words and the development of the keyboard. The computer-training program "Bridge to English" helps to solve these problems. Almost every task involves typing English words and sentences on the keyboard.

e). Working out grammatical phenomena.

All training computer programs somehow provide for the development of certain grammatical structures. The program "Bridge to English" has 20 lessons, and each lesson works out its own grammatical phenomena: affirmative, negative and interrogative sentences, degrees of comparison of adjectives, participle, passive voice, pronouns some, any, structures there is / there are, prepositions, etc. All types of work in one lesson are aimed at working out a certain grammatical phenomenon.

In the "Grammar" section of the "Professor Higgins" program, there are two sections: theoretical and practical. Checking the knowledge of the student, the program notes his progress, if necessary, prompts. The program "English Gold" ("Deutsch Gold") contains 144 microdialogues, each of which works out a certain grammatical structure, for example, Present Continuous is used in many dialogues, for example, a conversation between parents about their children who play in the garden. After listening to the dialogue, students reproduce it based on the image, then independently.

Composing grammar tests using a computer helps students better master the grammar material. High school students develop their own computer programs to test students ' lexical and grammatical knowledge.

Modern programs require students to concentrate, focus, and strain their memory. Not every student is able to work in this mode. Psychological characteristics of the character, the type of perception of the child become the reason for not being successful. At the same time, modern requirements for the level of education do not allow to reduce the amount of information necessary for the student to master the topic of the lesson. However, when organizing a lesson using computer programs, information is provided to students in a colorfully designed form, using animation effects, in the form of text, diagrams, graphics, and drawings. All this, according to modern didactics, makes it possible to explain the educational material more clearly and easily.

The use of ICT in English lessons, the use of new information technologies in teaching English helps us to choose methodological tools and techniques that allow us to diversify the forms of work and make the lesson interesting and memorable for students. They also make it possible to radically change the organization of the process of teaching children, to form their systemic thinking. In my work, I often use a variety of electronic resources: multimedia programs, materials found on the Internet, interactive tests. They make lessons varied and interesting, teach children to use various new technologies. On the Internet, you can find information necessary for projects: about museums, sights, information about current events in different countries, about the environmental situation in different parts of the world, about national holidays, etc. Moreover, these materials act as a "real" cultural carrier "in the process of intercultural communication. At the same time, my role as an English teacher is to adapt them to the given curriculum, the topic being studied and the language level of the students.

The use of ICT makes it possible to move from learning as a function of memorization to learning as a process of mental development; from a static model of knowledge to a dynamic system of mental actions; from an orientation towards an average student to differentiated and individual training programs; from external motivation of learning to internal moral and volitional regulation. As an English teacher, the goal of my work is to develop students ' abilities to use a foreign language as a communication tool in the dialogue of cultures and civilizations of the modern world. The formation and improvement of foreign language communicative competence takes place in the formation of the following components:

- speech competence (improvement of communication skills in four main types of speech activity: speaking, listening, reading and writing);

- the ability to plan your verbal and non-verbal behavior;

- discursive competence (the ability to build one's own statement in accordance with a given communication situation);

- linguistic competence (phonetics, vocabulary, grammar, development of skills in operating linguistic units for communicative purposes); sociocultural competence (knowledge about the socio-cultural specifics of Englishspeaking countries, the formation of skills to highlight the general and specific in the culture of the native country and the country of the target language); 
(the ability to get out of the situation in conditions of a shortage of language resources when receiving and transmitting foreign-language information);

- educational and cognitive competence (development of general and special educational skills that allow you to improve the educational activities for mastering the foreign language, to meet with this help cognitive interests in other areas of knowledge).

The educational space today is filled with computer training programs, which are developed by experienced teachers, programmers, psychologists and designers. They are a good help in learning and orient students to a free and independent pace of learning. Control of knowledge is carried out immediately with a guarantee of transition to a new level. The effectiveness of training sessions increases when using multimedia textbooks on electronic media.

In my work I use computer-based teaching programs in English (multimedia application "Enjoy Listening and Playing" for elementary school) for the teaching materials of M.Z. Biboletova et al. "Enjoy English".

This program can be used for both individual and collective work. It can also be used for independent work of students. The program "Enjoy Listening and Playing" is used when working with a projector, interactive whiteboard, computers. This program can be used for both individual and collective work. It can also be used for independent work of students. The program "Enjoy Listening and Playing" is used when working with a projector, interactive whiteboard, computers. The program is designed taking into account the psychological and age characteristics of younger students. The exercises are aimed at developing all types of speech activity. Special attention is paid to listening, the pronouncing side of speech. The following types of exercises are presented: listening exercises (introductory and testing the understanding of the content of the listened audio recording); exercises for the formation of a graphic and sound image of a word through a cartoon presentation and the activation of new lexical units; exercises for the formation of reading skills (introductory and training in use; the method of perceiving a word or phrase as an integral unit; finding a word on the screen by its sound; reading independently without relying on sound); exercises for the semantics of vocabulary and the development of spelling literacy; exercises for the formation of grammatical skills; exercises for the formation of a graphic and sound image of a word through a cartoon presentation and the activation of new lexical units [7].

In English lessons, with the help of ICT, we develop reading skills and abilities, improve the writing skills of schoolchildren, replenish the vocabulary of students, and form a stable motivation for students to learn English. Students of our school take part in quizzes, contests, and Olympiads held on the Internet. The use of ICT in the classroom helps to increase interest in the subject, helps students to overcome the psychological barrier to the use of a foreign language as a means of communication. For teachers, the Internet is just a lot of useful information! Here we can find a rich language and country-specific material, as well as a description of the latest educational technologies, the opportunity to constantly improve their own level of language proficiency, communicate in English and introduce their students to this.

The practical use of ICT involves a new type of cognitive activity of the student, the result of which is the discovery of new knowledge, the development of cognitive independence of students, and the formation of skills to independently replenish knowledge, search and navigate the flow of information.

Of course, in foreign language lessons, you cannot use a computer all the time, since there are many other tasks that can be solved only with direct communication. Nevertheless, the role of such lessons should not be underestimated. Practice shows that, thanks to the multimedia accompaniment of classes, the teacher saves up to $30 \%$ of the teaching time than when working at the blackboard. He should not think about the fact that he does not have enough space on the blackboard, do not worry about the quality of the chalk, whether everything written is clear. By saving time, the teacher can increase the density of the lesson, enrich it with new content. When explaining new material in the lesson, the teacher can use subject collections (illustrations, photographs, portraits, reproductions of paintings by the studied artists, video tours, video fragments), dynamic tables and diagrams, interactive models, projecting them on the big screen. At the same time, the technology of explanation changes significantly -the teacher comments on the information that appears on the screen, if necessary, accompanying it with additional explanations and examples.

1. Education and the XXI century: Information and communication technologies. - M.: Science; 1999. - $191 \mathrm{p}$.

2. Rudenko-Morgun O.I. "Computer technologies as a new form of education"

3. Nosenko E. L. "Application of IT in education"

4. Fadeev S. V. "On the issue of using a computer in teaching foreign language"

5. Leont'ev A. A. Needs, motives, emotions. Lecture notes. - M .: Publishing house of Moscow State University, 1971

6. Vartanova I.I. "On the problem of motivation for educational activity" Vestnik MGU Series 14 Psychology 2000 №4 p33-41

7. V.O. The use of computer technology in English lessons. -English language at school No3 (11), 2005. - p.64 